\title{
The Iconography of Disruptive Bodies: Social Media and Medical
}

\section{Identities}

\section{$\underline{\text { Abstract }}$}

As an artist I examine how photographs discipline an individual' s relationship to her or his body and society. Working on the premise that the idealization of certain bodies has led to a reduced visual language of expression for the body, I explore ways of expanding this iconography.

As a historical backdrop to this study I will discuss photographs created in La Salpêtrière hospital in the late-nineteenth century. During this time, the women who best performed the contorted shapes of hysteria were photographed for the Iconographie photographique de la Salpêtrière (Charcot). Film stars began to imitate the women in the photographs, and the gestures of hysteria transformed popular expressions of passion.

In contemporary culture, online social networks mediate our relationships; we present ourselves to others in a series of two-dimensional images. In the virtual realm, the role of photography could be viewed negatively because it fixes the individual, creating a permanent record of a self that can be judged using the quantifiable system of likes and favourites. But the selfie is also creative; it offers unlimited possibilities of performance and self-expression.

In this chapter I examine the cyclical relationship between body ideals, online social networks and individual bodies by exploring the selfie’ s potential for self-creation, performance and masquerade. Alongside the 'healthy' productive body I will consider illness as a form of unconscious protest, referring to hysteria and its contemporary counterparts, binge and restrict eating disorders. Using the Foucauldian notion of the disciplined body, I will theorize online social networks and selfies as potential sites for disruption of hegemonic body-image ideals.

\section{$\underline{\text { Keywords }}$}

Identity, Gender, Medical, Eating disorder, Selfie, Hysteria, Salpêtrière, Socialnetworking, Photography, Performance. 


\section{The Iconography of Disruptive Bodies: Social Media and Medical Identities}

\section{$\underline{\text { Ideal Consumers }}$}

Marx says 'the machine accommodates itself to the weakness of the human being in order to make the weak human being into a machine' (p. 85). Capitalism turns me into a commodity that consumes and is consumed. Through the consumption of commodities I improve the appeal of my body and turn it into a display case for sign-values. Objects are not purchased because of use or exchange value but because of the social prestige they bestow upon the owner (Baudrillard, pp. 29-30). I participate in a system of sign-value exchange that reinforces existing social norms and structures. Through multiple discourses, from medicine to popular culture, the dominant classes impose their body standards on me, and by adhering to the standard I disseminate it further. Baudrillard called the process in which the dominant classes control the signvalue of objects "semiotic privilege" (p. 116). My body does not escape this process of signification.

The healthy body acts as a sign-value for success, a strong work ethic and self-control; it is viewed as a productive resource and medium for creating bodily capital” (Dworkin and Wachs, p. 104). The unhealthy body signifies a lack of self-control and is deemed to be an obstacle to productive labour. There is a conflict at the heart of consumer culture between the imperative to work hard and delay gratification, and the consumer dictum of instant pleasure. Fitness and working out demonstrate my ability to balance these opposing forces (Crawford, p. 92). Health is a way of exerting control over the population, transforming leisure into a form of body labour that compliments the individual 's economic function.

To further disseminate the healthy body ideal and deter resistance to it, confession and shame are used as mechanisms of coercion. In terms of health, the confessional body signifies a person with the financial resources to undertake self-analysis and self-improvement practices in order to achieve bodily capital. The act of confession "exonerates, redeems, and purifies $\cdots$ it 
unburdens of wrongs, liberates and promises salvation" (Foucault, pp. 61-2). In contrast to this, shamed bodies, traditionally working class, poor and other marginalized people "are subjected to the 'bio-power' of experts who impose upon these bodies judgments that explain their pathologies and failures " (Dworkin and Wachs, p. 14). Shamed bodies are viewed and manipulated by others while confessional bodies are self-regarding and able to create themselves.

In capitalist societies the body is scrutinised in order to identify " problems" and then commodities are developed to solve them. Many commodities tempt me with the promise that I will "feel better," implying that my health will be improved by the act of consumption. But the subtext of the advertisement is frequently that I will feel better because I will experience increased social value due to an improvement in my appearance. Rosalind Gill describes this trend referring to Nike' $s$ "Just Do It" campaigns:

The fetishization of fitness is arguably more pernicious than that of appearance because we are interpellated as morally responsive for how well we do. If we don' t have the looks of a fashion model we may be less socially valued but it is not entirely our fault. But if we don' $t$ 'keep in shape' we are culpable: we let ourselves go - the most dreaded sin of contemporary affluent societies. The advert urges us to reject external templates of beauty, whilst simultaneously enrolling women in a regime of disciplinary power in which they become morally responsible for disciplining their own bodies, and where beauty work is redefined in terms of health and pleasure (Gill, pp. 86-7).

By camouflaging beauty standards as health standards advertisements can preemptively counter complaints about sexism and objectification. At the same time, health is viewed as a personal responsibility, achieved through commodified leisure activities that conceal health inequalities related to class and race. Feminist discourse relating to empowerment is subsumed into a 
consumer discourse of self-interest and narcissism, and the healthy body supplants the desirable body.

In the process of examination, dissection and improvement by an interminable succession of commodities, I am alienated from my body. I come to view it as an external object that must be managed and controlled by consuming the correct products. My body is fragmented into sign-values and transformed into a commodity-fetish when signs of individuality are eradicated in the production of a socially acceptable surface. When defining the commodity fetish Baudrillard returns to the original meaning of the term:

a fabrication, an artifact, a labor of appearances and signs. What quickly becomes apparent is the aspect of faking, of artificial registering - in short, of a cultural sign labor - and that this is the origin of the status of the fetish object, and thus also plays some part in the fascination it exercises. (Baudrillard, p. 91)

The term "fetish" comes from the Latin facticious meaning "to make" and the Portuguese feitico meaning "artificial" . It had a dual meaning: as an adjective it meant artificial, human-made and in some cases, fraudulent. As a noun it refers to idolatry, an act of witchcraft, or an object of enchantment. In “ The Origin of the Fetish" William Pietz describes how the body was also sometimes considered to be a fetish. In “De Spectaculis” Tertullian designated wrestling and bodybuilding as forms of fetishistic body enhancement that produced “an artificial body so as to surpass God' s work $"$ (qtd. in Pietz, p. 26).

In contemporary consumer culture the body is similarly manufactured through the process of commodification and body maintenance. Its function as an object of enchantment is two-fold; for the individual who carries out the extensive "body-work" the body is the main focus of her or his attention; and, because the healthy body is synonymous with the desirable body, it also charms and bedazzles those around it. It functions as both meanings of the feitico. 


\section{Sign-Body Exchange}

Evidence of the preoccupation with, and enchantment by, the commodity-fetish body might be discerned in the phenomenon of self-presentation known as the selfie. The proliferation of mobile phones with cameras has enabled large swathes of the population to take and share photographs of themselves taken by themselves. The subject is no longer the absent object of their photographic mementos. However, a web search reveals that the most common form of selfie is not a souvenir of a place or event but a record of the individual in seemingly private spaces. Some form of confessional practice might be suggested when an individual presents her or his body in the virtual realm for the scrutiny of unknown observers. Why else would multiple social media websites offer so many quantifiable ways to demonstrate that a photograph has been viewed and a value judgment made? People gauge the "success" of their selfies on how many "likes", "favourites", retweets, and "shares" they receive. This is how the currency of the body is determined, and how shaming looks enforce bodily norms. Selfies also disseminate sign-value; body ideals and fashion trends are perpetuated in the exchange of images on social media networks.

Selfies often seem uncomfortably intimate because a lone figure is located in a private space, such as a bathroom or bedroom. The camera is visible, reflected alongside the body making all aspects of the look manifest; I see the reflection the posing subject also sees, we both view the individual as an image. Object and viewer are flattened into one viewing position; all are equal. As I can see the camera-phone in the photograph I am denied the position of active recording device and powerful unseen observer. Instead I am pushed into the place of a mirror image, and my identification with the body in the photograph is increased.

In Lacanian psychoanalysis the mirror phase marks the individual' $\mathrm{s}$ entry into the visual realm. At first an infant lacks the motor skills needed to fend for her- or himself and experiences its body as fragments that are indistinguishable from the rest of the world. During the first year of life the infant is held in front of a mirror and told "there you are." By apprehending itself as an image of a complete body, the infant is able to define its own 
boundaries and begins to master its body. As Joël Dor describes: "In recognising himself through the image, he is able to reassemble the scattered, fragmented body into a unified totality, the representation of his own body" (Dor a, p. 96). Because the infant is still dependent on others, the unified body is anticipated rather than experienced. As a result, the infant is simultaneously captivated by an image of its body and alienated by the superiority of the image that it cannot live up to. The recognition of self as subject and object produces a split. The subject tries to reconcile "self" with the image by identifying with and emphasising favourable characteristics viewed in other people and repressing unfavourable ones. The subject is a work of idealization and denial of unconscious knowledge that the self is lacking or incomplete.

If an individual is unable to assimilate aspects of other people' $\mathrm{s}$ identity, but identifies with them so powerfully that they try to become exact copies of that identity, s/he may be hysterical. According to Juliet Mitchell, hysteria is not caused by intergenerational conflict between child and parent but lateral rivalry between siblings and peers. A sibling rival threatens the hysteric' s position as a unique child. The hysteric feels displaced and absent; the anxiety caused by this emptiness of self is temporarily relieved by powerful identification with, and jealousy towards, the rival. There is an aspect of oneupmanship because the hysteric is desperate to gain superiority over the rival who is deemed to be better and more loved. This leads to an escalation of behaviour (Mitchell, p. 137).

Mitchell goes on to describe the hysteric' s seductive, attention-seeking behaviour as an excessive presence. The hysteric "neither remembers nor expects to be remembered if he is not always present - so he always over insistently presents himself " (Mitchell, p. 212). When threatened by displacement by a rival, the hysteric unconsciously retaliates by splintering her/his identity into fragments. This fractured personality fends off the threat of absence and annihilation by forcefully presenting multiple aspects of the self in a way that is unavoidable for others.

In capitalist societies the commodification of the body supports and encourages hysterical identification. Advertisements address the consumer in a 
way that appeals to her/his hysterical tendency and enables it to develop; adverts encourage jealousy and rivalry between peers. The viewer of an advert is led to believe that the people in the advert are superior because they possess the commodity in question. The consumer is encouraged to continually judge her/his self in relation to others and resolve inferiorities through consumption of commodities. When individuals standardize their bodies to the ideal aesthetic of their social group, the body becomes increasingly difficult to differentiate from others, further enabling hysterical identification.

Consumers are also encouraged to view the commodities they purchase as carriers of meaning relating to identity, feelings and relationships with others. It seems it is the commodities that express, feel or think in the place of the person. Because identities are increasingly created through commodity consumption, consumers may unconsciously feel absent or empty of meaning. The consumer may feel that a rival commodity has displaced them. If the consumer believes s/he will absorb the values attributed to the commodity, identification with it may be hysterical. The dread of non-existence that results from this commodity identification is warded off by an endless series of mimetic, hysterical identifications with commodities: a compulsion to consume.

For a brief period of time I created selfies and shared them online. I followed the "selfie" hashtag on Twitter to try to understand the appeal of producing this form of self-portrait. I discovered that a large number of followers on Twitter are commercial enterprises posing as people. They search under the "selfie" hashtag to target individuals with make-up, fitness programmes and cosmetic treatments claiming to help them achieve an ideal look. These commodities are also promoted using the "selfie" hashtag, so the distinction between the body and the commodity is totally erased; it implies that the commodity is already a part of the consumer.

Perhaps selfies are an inevitable response to this culture. Poses, gestures and facial expressions are mimicked and exaggerated, suggesting that selfie producers are trying to out-do, or perhaps more accurately, out-sexualise each other in an endless search for a stable identity as the object of desire for another. 
In some selfies a person poses between two or more mirrors that multiply the body. One is able to see different angles of the body, as if one inhabits more than one viewing position. This type of photograph could suggest a hysterical form of self-presentation in which the subject rejects that the body is incomplete or lacking and "dreams of a perfect erotic body that could display itself as a whole” (David-Ménard, p. 130). Psychoanalysts such as Monique David-Ménard and Joël Dor suggest that the hysteric is only able to acknowledge her or his desire through the desire of the other. By attempting to become the object of the other' s desire, the hysteric often searches for a form of body modification that "would adjust their image to their ideal" (Catherine Millot qud. in Dor b, p. 193). Paradoxically, the need for a fantasy body modification proves the lack that is denied. These selfies fragment the body in a way that could be interpreted as an illusion of completeness and the excessive presentation of a splintered subject.

In Structures and Perversions Dor recounts the case of a hysterical woman who fantasises that a male friend unexpectedly visits her. In the fantasy she goes into the bathroom to make herself presentable and "would enjoy imagining, with a delight she could not explain, what her friend might think she was doing in there" (Dor b, pp. 24-5). The fantasy always ended abruptly at this point; of not knowing. Dor says this scene signifies an essential characteristic of hysteria, the donning of a mask in order to place "herself at a distance from herself and thus from her desire, so that she may remain in ignorance of this desire" (Dor b, p. 26). By seeing herself in the mirror, she is able to view herself as an external object, an object of desire for the other, without acknowledging that she has desire of her own. Multiple screens impose distance; mirror surfaces and closed doors ensure that desire is only ever imagined and remains unsatisfied. This connotes what Dor describes as the " hysterical pretence" in which "the subject' s desire is always there, but only provided it gets itself represented where it is not by finding a proxy in the desire of the other” (Dor b, pp. 25-6). The hysteric' s desire is designed to bring the other person' s desire into existence; it disappears as soon as the desire of the other is shown. As an example, Dor recounts the actions of a hysterical woman 
who spends time in an area populated by prostitutes. When a potential customer approaches her she replies "You' re making a mistake, I' m not that kind of woman" (Dor b, p. 137). She may seem to want to act upon desire but this is a hysterical pretence, she wants to be desired rather than participate in a desiring relation.

In the production of mirror selfies, a lone figure photographs her or his body as a reflection and disseminates it to an unknown audience via social media networks. The photograph has not been taken because the individual wants to know how she or he looks at that particular moment; rather, its purpose is to capture the mirror image $s /$ he has already apprehended in order to make it visible for someone else. By literally putting her or his self in the picture, s/he seems to be trying to meet the gaze, to see her/his own body from the place where the other looks at it. The question "is this what you want me to be?" is answered in the form of "likes" , "favourites" , retweets and " shares".

Hysterical pretence seems to have found its visual form in selfies. Unlike the woman hysterically identifying with a prostitute, the selfie producer is only required to appear desiring, the distancing effect of virtual interaction means the hysterical pretence is not exposed. The object of desire is able to offer itself, safe in the knowledge that it will not be called upon to satisfy desire. Selfies enable a hysterical individual to repeatedly and insistently present the self to a mass audience. Because gestures and actions are mimicked and exaggerated in selfies, they are an expression of hysterical identification and the method of transmitting hysteria through peer groups. As Mitchell says, symptoms today would be "mass experiences in an era of mass communication" (Mitchell, p. 121). She goes on to state:

Today the social situation which favours a conscious, public enactment in place of private driven symptoms is best summed up in the philosophy of post-modernity which eschews metanarratives, truth, representation in favour of fragmentation, the proliferation of desires, the ascendancy of the 
will and the act and language that gets one what one wants. This is the valorisation of performance and performativity (Mitchell, p. 133).

Post-modern, capitalist societies reward the behavioural traits of hysteria' $\mathrm{s}$ hyper-sexualised narcissism. Selfies enable individuals to make hysterical demands for attention to a mass audience. Hysterical demand is met with hysterical identification and a global outbreak of hysteria results. As Juliet Mitchell proposes, hysteria is becoming the norm (Mitchell, p. 133).

\section{Celebrity Selfies}

The phenomenon of the selfie may have begun with the celebrity selfies in which celebrities share photographs of their private lives with online followers. Celebrity selfies often have a commercial imperative beyond the production of bodily capital, whereby celebrities photograph themselves with own-brand commodities or products they have been paid to endorse. Media outlets, such as The Daily Mail Online, frequently feature celebrity selfies alongside a "Fashion Finder" section that directs viewers to online shops where they can purchase the outfits worn by celebrities. The message is clear: through commodification you can turn yourself into the image.

In an article about cosmetic surgery and the "fashionable face," Meredith Jones discusses the increasingly blurred boundary between real flesh and virtual representations of the body. Because people tend to select the "fashionable faces" they wish to emulate from magazines, the type of face that is idealised is "visibly manufactured" (Jones, p. 194). A manufactured face is created with studio lighting, makeup, digital manipulation and cosmetic surgery. Our standards of beauty, for the body as well as the face, are based on stylised and manipulated images rather than flesh bodies in the real world. When individuals identify with selfies they do not wish to copy the celebrities who produce the photographs; instead they attempt to replicate the photographs.

The selfie is a form of advertising and sign-value exchange, but one that I believe to be more insidious than mainstream, professionally created imagery. Selfies have a spontaneous quality and are frequently taken in the home. The 
viewer identifies with the photograph because the activities bear some resemblance to her or his own daily routine. The seemingly un-posed moment obscures the commercial basis of these images. An image-literate audience knows the bodies in advertising and magazine images are created by teams of hairdressers, makeup artists and digital re-touchers, but the selfie masks this construction. It seems to present the celebrity body as already perfect without the need for pre- and post-production work. The celebrity selfie implies that a flawless body is actually achievable at a time when the ideal bodies of both men and women are impossibly thin in some areas and rounded and muscular in others. They are montage bodies created by commodities and surgical enhancement. Because these artificial bodies are presented as body ideals they act as advertisements for the products and procedures used to create them.

Not only does the selfie appear spontaneous and unadulterated in comparison to an advert, but also the manipulation that is expected and accepted in advertising is reviled in photographs on social media networks. Whenever I put "selfie" into a web search, the list of suggested searches inevitably includes "selfie fails" . Occasionally they are bad taste selfies (those taken in Auschwitz or at Nelson Mandela's funeral, for example) or images where something embarrassing has been inadvertently revealed, but on the whole they form a catalogue of digital manipulation disasters. Men try to make their muscles bigger and their stomachs flatter, while women sculpt their bodies to an unachievable hourglass shape. A lack of technical knowhow gives them away; the tiles and furniture behind the figure also warp and bulge exposing the attempted fakery.

In order to uncover the artifice in selfies taken by individuals who are skilled using photographic manipulation techniques, a piece of software called Mito Restore has recently been developed that returns manipulated images to their original state. The message is clear: your photographs will not lie for you. Presenting an ideal fantasy in the virtual realm is now less satisfying because Mito Restore has undermined the fantasy. There is no escape but to actually try to achieve the impossible body ideals prescribed by celebrity selfies.

The desire to become a "living image" is encouraged in consumer culture. Commodity manufacturers claim to create cosmetics that produce effects 
equivalent to Photoshop techniques. Revlon says its "Photoready" makeup will "airbrush" skin to make it appear flawless (Jones, p. 204), while products such as "All in One InstaBlur" by the Body Shop and Garnier's "5-second Blur Skin Smoother" claim to reduce the appearance of pores using "blurring" or "liquefying" technology. These products indicate that anxiety is caused by increasing opportunities to be photographed and to photograph one's self. They also demonstrate a desire in the consumer to reduce the difference between the real face and its 2-dimensional image. When these products fail to recreate the perfection of the image, cosmetic surgery is the only remaining real world equivalent of the digital manipulators toolbox.

Negative peer reviews on social media websites and technological advancements that reveal digital manipulation in photographs seem to remove any possibility of the selfie being a site for self-transformation, creation and disguise. The pressure to create the fantasy/ideal body in reality undermines the idea that the individual is only limited by imagination. When reality fails to live up to body image ideals, it is the real body that is changed. The sign-values of the body are not expanded in this process, only condensed and exaggerated through a process of hysterical identification.

\section{Hysterical Selfies}

In the Salpêtrière hospital in the nineteenth century, hysterical gestures and poses were enacted and re-enacted for an audience. As with the responses received by individuals who post selfies on social media websites, the hysterics of the Salpêtrière were also able to gauge their ability to become the object of the other's desire based on audience responses. Asti Hustvedt describes how “ the best performers attracted large audiences and their shows even went on the road, travelling to other hospitals and amphitheatres" (Hustvedt, p. 92). The hysteric' s knowledge of this popularity is described anecdotally in instances of primadonna behaviour amongst the patients. For example, in a memoir Alphonse Daudet describes a scenario in which Balmann, the pseudonym he used for Blanche, "the Queen of Hysterics," refused to take to the "stage" during one of Charcot' s lectures because a less beautiful and less talented 
hysteric had been brought out before her (Hustvedt, p. 35). It seems she and the other hysterics were aware of how desirable their symptoms were, which is likely to have contributed to the condensation and refinement of the iconographic poses.

Although Charcot dispelled the myth that hysteria was a female malady, the symptoms displayed by hysterical patients seemed to simultaneously reinforce and confound social expectations of bourgeois gender roles. At a time when the ideal middle or upper class woman tended to stay at home, without voicing her own opinions, and repressed the sensations of her body, the hysterical symptoms of loss of voice, paralysis and anaesthesia could be viewed as concrete enactments of social restriction upon the body. As the students of the Salpêtrière were told, "one might even say that hysterics are more womanly than other women" (Charles Richet qud. in Kaplan, p. 458). Through an iconography of aberrant gestures the hysterical patient attempted to be the object of the other' $s$ desire. By alternating between performances of sexual provocateur and saintly religious devotee the hysterical women brought attention to the artificiality of these constructions.

This spectacular illness captured the public imagination; representations of hysterics were not only found on the walls and in the cabinets of the Salpêtrière, but also filled the pages of newspapers and novels, and populated performances on stage and screen. Charcot's lectures were very popular, attracting tourists, journalists, writers and actresses as well as doctors and students. Even the famous actress, Sarah Bernhardt, spent time in a cell in the Salpêtrière while preparing for a stage performance. The hysterics achieved circumscribed celebrity status, and their passionate hysterical gestures were transmitted to the public through popular culture. Socially acceptable feminine behaviours took on an aspect of the aberrant body. If " hysteria became every woman’ s expression of intense passion” (Appignanesi , p. 378), perhaps society women also unconsciously protested against the restrictions of femininity. If this is so, hysteria could present a model for a positive contagion when it passes from pathological illness to popular culture. 
Through a process of idealisation and identification the gestures of the hysterics became standardised and exaggerated. It appears that the reduction of poses and facial expressions to a legend in selfies could also draw attention to the artificial construction of the body as a commodity-fetish. Perhaps the selfie can be read ironically.

\section{Dialectical Signs}

If selfies suggest that an individual is presenting her or his body in a hysterical denial of lack, the structure of the commodity-fetish encourages this hysteria. The commodity is characterised by lack; as a commodity-on-display, the superficial appeal of the surface conceals a deficit of quality that results from mass production techniques, and as a sign-value the object is a signifier which points to, but does not actually possess, the quality that is signified. The commodified body is also subjected to this process; it loses individuality, and the promises made in advertisements of health and status are not always fulfilled. The sign-value of the commodity-body serves to conceal lack with a positive sign. In For a Critique of the Political Economy of the Sign, Jean Baudrillard suggests that use-, exchange- and sign-value define

a full, positive world, relentlessly completed by the plus sign: the logic of surplus value (inseparable from value). It is a world in which man is incapable of selling himself short $\cdots$ Value is totalitarian. It excludes ambivalence, as well as any relation in which man would cease to complete himself in value, or index himself according to the law of equivalence and surplus value (Baudrillard, p. 206).

In order to destabilize a sign-value system populated with positive signs, ambivalence must be introduced with negative signs. When describing the dialectical potential of Surrealism, Benjamin suggests that the montage' $s$ power lay in its un-reconciled and disharmonious elements, creating a contradiction that enables them to simultaneously express utopian idealism and its cynical denial (Benjamin qud in Buck-Morrs, p. 144). In order to disrupt the 
sign-value of the body and become truly dialectical, selfies must simultaneously present a positive and negative sign.

Bodies in various stages of undress are not the only signs in selfies. The banality of the things that surround them actually seem to reveal more than the bodies themselves. The objects are all part of the presentation; the hair clips, cosmetic bottles and clothes strewn across the floor provide a narrative of the construction of the body as an image. The objects are signs of the labour that has taken place; they reinforce the body as a commodity-fetish. In Benjamin’ s terms, they produce the "profane glimmer [that] makes the commodity phosphorescent" (Benjamin, p. 131). The loss of quality (or individual human characteristics) that results from mass production is concealed by an overdetermination of the surface. By presenting the objects used in the process of manufacture, the illusion of the body is brought to the viewer' $s$ attention.

According to Lacan, there is a fracture or split in each person between the "being and its semblance, between itself and that paper tiger it shows to the other" (Lacan, a, p. 107). The "paper tiger" functions as a lure or a form of intimidation when the individual is trying to seduce or fight another person. In these kinds of selfie the juxtaposition of products that assist in the construction of a "mask, a double [ $\cdots]$ a thrown-off skin" (Lacan, a, p. 107) strengthens the notion that the body presented in the photograph is just that, a semblance or a creation. The position of the body as the object of the other' $s$ desire is undermined if the semblance becomes too apparent before seduction or domination takes place.

There is creative and disruptive potential in the gap between being and semblance. There the body oscillates between a docile object with the potential to satisfy desire and a false image that will fail to reciprocate desire; it seduces the viewer with a body that does not exist.

In Womanliness as Masquerade Joan Riviere describes how a successful academic woman seemed to undermine her intellectual abilities when lecturing in front of her male colleagues. Instead of displaying her authority and commanding the respect of her peers she became "flippant and joking, so much so that it has caused comment and rebuke (Riviere, p. 308). She wore her 
femininity as a disguise that concealed her intellectual brilliance to reassure the men in the audience that she was still only a woman. However, Stephen Heath points out that the masquerade of femininity does not constitute submission to patriarchal authority. The men who witness her masquerade are simultaneously reassured because she is acting as they expect and disturbed because they know she is a fantasy. The masquerading woman is illusory and does not really exist (Heath, p57-8). In Mad Men and Medusas: Reclaiming Hysteria Juliet Mitchell attributes the academic woman's masquerade to hysteria. She argues that because Lacan used Riviere's theory of masquerade to theorise all femininity as masquerade - "La femme n'existe pas..." (Lacan, b, p. 68) - hysteria was subsumed into femininity. All femininity became hysterical and the diagnosis of hysteria was banished to medical history (Mitchell, p. 187).

The objects that surround the figure in some selfies are the tools for turning the body into an enchanting object and the means of exposing it as a fraudulent construction; a feitico. The hysterics' excessive “presentification ” also points to the artificiality of the performance of gender identity. They provide evidence that the body in the photograph is "a labour of appearances and signs ” (Baudrillard, p. 91). Desire is provoked and potentially extinguished; the sign-values communicated by these bodies could also be introjected or rejected by the viewer depending on her or his response to the image. In the process of disavowal the negative signs are apprehended and denied, imposing unconscious acknowledgement of them. This is the potential power of the selfie, a demonstration of how aberrant signs can be smuggled into the system of sign-value exchange using the distracting, enchanting nature of the commodity-body fetish.

Didi-Huberman says that the iconography of hysterical poses was always becoming more demonstrative, in high colours $\cdots$ according to its distinguished character of a pact, and of connivance, too. ( 'Connivance: connivere: means at one and the same time: I wink, I blink, I close my eyes.' )” ( Didi-Huberman, p. 171). The wink suggests a flirtatious action designed to court the gaze of the other. It is a signal, an invitation and a gesture of complicity. It is also a sign of mockery and a display of knowledge designed to highlight a 
deficit of knowledge in someone else. It is a gap between two opposing signs, a blind spot in which other aberrant, disruptive gestures could be inserted.

If selfies are viewed as an ironic parody of the commodification of the body in capitalism, they could challenge hegemonic body ideals. But irony is simultaneously positive and negative toward its object. The object is "both rejected and introjected, negated and preserved" (Schor, p .97). The sign-value of the body as a commodity fetish continues to circulate. In The Arcades Project Walter Benjamin suggests that consumers can appropriate commodities as wish images" of a different, and perhaps, revolutionary social order:

For this to occur, estrangement of the commodity from their initial meaning as use-values produced by human labour is in fact the prerequisite, it is, after all, the nature of the allegorical object that once the initial hollowing out of meaning has occurred and a new signification has been arbitrarily inserted into it, this meaning "can at any time be removed in favour of any other” (Benjamin qud. in Buck-Morss, pp. 1812)

In order to be transformed into a "wish image" and agent of change, the body must be divested of the sign-values of capitalism and filled with a different significance. If health is intertwined with ideas of sexual objectification and is deemed to a be an empowering choice of the individual, perhaps ill health offers a significance that escapes this sign-value exchange.

\section{Negative Signs}

Lack of health suggests the individual is unable to balance the conflicting demands of production and consumption. Robert Crawford describes:

On one hand we must repress desires for immediate gratification and cultivate a work ethic, on the other, as consumers we must display a boundless capacity to capitulate to desire and indulge in impulse; we must hunger for constant and immediate satisfaction. The regulation of desire 
thus becomes an ongoing problem, constantly besieged by temptation, while socially condemned for over indulgence (Crawford, p. 199).

The imperatives to over-indulge in celebration and control the body against its appetites could be read in the extreme eating habits of addiction ${ }^{1}$ and restriction. The requirements of capitalism are taken to pathological extremes; they produce bodies that expose the contradictory messages of consumerism.

The anorexic consumer type implies a disharmony between production and consumption, in which consumption is drastically minimized and bodylabour, such as exercise and calorie-counting, is valued to an excessive level. Because it is fundamentally a refusal to consume, consumer society attempts to discipline the anorexic body. Medical intervention by the state tries to transform the anorexic body into a consuming body because significantly reduced consumption is unacceptable in consumer society, and the excessive bodylabour of the anorexic can be fatal. Rather than undermine the anorexic' $s$ body-labour work ethic it is redirected toward health and fitness. In the clinic exercise is restricted, because eating disorder sufferers often use it to compensate for calorie consumption. The patients must reach a particular weight (known as their "exercise weight" ) to be deemed medically safe to exercise (Gremillion, p. 388). Exercise is simultaneously a symptom of illness and a method of recovery. By negotiating a compromise between consumption and exercise, the value of thinness is maintained, but the way it is achieved becomes productive. Inpatient clinics reinforce preoccupation with weight and calorie counting while teaching patients how to manage their consumption in order to remain within the lower limits of the socially acceptable body ideal.

The diet industry attempts to commodify self-starvation by advertising appetite suppressants and metabolism boosters on "thinspiration" websites. Thinspiration" or “pro-ana” (pro-anorexia) websites are blogs created by individuals with eating disorders. The writers share stories about their own

\footnotetext{
${ }^{1}$ I am using the term food addict rather than binge eater because this is the terminology increasingly used in eating disorder research centers. Although it does provide a frame of reference for a relationship to food that is beyond the control of the sufferer, it can appear to reduce pathological illness to physical symptoms.
} 
weight loss regimes, provide tips on how to lose weight and how to evade detection by doctors, family members and friends. They frequently contain “ thinspiration" or "thinspo" pages with images of their own emaciated bodies, images of other eating disorder sufferers or very thin celebrities. Many pro-eating disorder websites suggest methods of distraction or rewards for resisting food that are also couched in terms of consumption and bodywork. Visitors to one website are encouraged to undertake some of the following activities to prevent them from giving in to hunger pangs:

Exfoliate your entire body, take a long hot bath, pluck/wax your eyebrows, paint your finger and toe nails, use crest white strips, apply self-tanner, try a new hairstyle, have your hair cut, straighten your hair, give yourself a makeover with totally different makeup, shave/wax your legs, put a face mask on, go for a manicure or pedicure (Unknown, Pro-ana Distractions).

The creator of this website also suggests visitors search online to "find something you love, and get it once you go x number of days without binging." Another suggests that the readers calculate how much money they have saved by not buying food and reward themselves with a shopping trip for smaller sized clothing (Unknown author, My Diet Distractions and Tips for Not Eating). These recommendations turn self-starvation into an activity that enables consumption of commodities and produces sign-value for the body. Capitalism pursues the anorexic through illness and health.

The anorexic produces the self as an acceptable and unbearable image, fixating on a slender ideal but distorting the sign-value of the body in the process. This body interrupts the repetitious order of consumerism and the commodified body ideals imposed by it. It is handcrafted and demands a look that is also specifically created for its form; a generic look will not do. As Susie Orbach says:

She demands to be related to originally. Reflexive responses - for example, flirtatious or patronizing ones from men, or the "once over" from 
another woman who needs to position herself $\cdots$ - are confounded. She defies easy, comfortable definition $\cdots$ She is now looked at, not as someone who is appealing, but as some-body one cannot take one' s eyes off [ $\cdots]$ A presence which demands a response rather than a reflex (Orbach, b, p. 68).

The anorexic body disrupts the process of projection and introjection. Psychoanalysts describe anorexia as a failure of identification, and an inability to introject images from outside. In "Anorexia and Femininity" Pierrette Lavanchy describes the anorexic relation with the external world:

Anorexic persons profess that they want to present a different image in respect to the one people want them to present. But as their personal wishes are so much enmeshed with other people' s opinions, they cannot find an angle of themselves that is not inhabited by (and contaminated with) others' thought of desire. Therefore they can express what they want only as a refusal of models (Lavanchy, p. 115).

This refusal of models could also be interpreted as a refutation of the commodified sign-value of the body and its dissemination via hysterical identification. There is a repudiation of the creative potential of consumerism, in which the individual demonstrates their prestige by the selectivity of their purchases. These consumers do not create themselves through consumption.

The anorexic body annihilates the sign-value exchange system by reflecting the lack that is denied in the hysterical, commodified body. The signvalue of the body is circulated through the system of exchange. When I identify with another body, I acknowledge equivalence as I seek out the differences that provide my own body with differential value. The anorexic body disrupts the notion of similarity; the "like-me" that enables the designation of better or worse is stopped in its tracks. Its uniqueness functions in a way that is difficult to define; it seems to inhabit an entirely different value system outside the law of equivalence and surplus-value. 
Baudrillard argues that symbolic exchange annihilates the positive value of consumer society. In symbolic exchange the objects are gifted and re-gifted but never possessed or used. The value system is annulled because neither party gains from the exchange. It could be argued that the anorexic as an aberrant consumer prevents the use of the body as a surface for the communication and exchange of signs because it will not introject external signvalues and prevents others from identifying with and assimilating what it signifies.

Perhaps this can be demonstrated by the phenomenon of thinspiration, the large volume of photographs devoted to the celebration of extreme thinness. Individuals post selfies that emphasise their skeletal forms; they are clearly proud of the work ethic implied by their bodily transformation, but they do not construct the viewing positions created by other selfies. Despite the importance of the body in thinspiration it is rarely shown in its entirety - frequently the body is depicted without a head.

This relation to the body could signify a regression to "the fantasy of the fragmented body," a stage in early life prior to the unifying mirror phase. But visible muscles and bones create the impression of a hard surface that will not be penetrated by others. As Lavanchy states:

[anorexics] experience the other' $s$ influence in their body as an invasion or a contamination. The more they feel their mind soft and ready for surrender, the more they want to reduce their body to hard bone (Lavanchy, p. 120).

This does not seem to indicate an inability to distinguish self from other; the borders are clearly defined and resolutely patrolled. Nor does it suggest hysterical fragmentation caused by an unconscious fear of displacement. Identification is denied; the individual is given anonymity by their decapitation and the look of the viewer is disarmed because it cannot be returned. In the process of identification the viewer tries to position her or his self as inferior or superior to the body in the image but is unable and so the exchange of sign-value is denied. 
A similar disfigurement takes place in the photographs of patients with hysterical anorexia at the Salpêtrière hospital in the nineteenth century. These photographs may have been defaced to protect the identity of the patient because of the nudity of their bodies, but the coarseness of their treatment - at once aggressive and unsuccessful - strikes me as defensive. Susie Orbach describes the experience of viewing an anorexic body where "anguish and defiance combine in the most curious way to make the observer passive and motionless in response. There is a simultaneous desire to retreat and move in closer. The conflict renders me immobile" (Orbach, b, p. 79). I wonder if the doctors and photographers at the Salpêtrière also experienced passive and motionless horror when viewing the hysterical anorexic body. Perhaps this is why they chose to disfigure them.

\section{[PLACE ILLUSTRATION 1.1 (S) HERE]}

1.1 Two Photographs of a Woman Suffering from Anorexia (1888-1918) Nouvelle Iconographie de la Salpetriere. [Journal] Wellcome Library: London.

Maybe this is the dialectical power of the body, demonstrating where its spectacularisation might lead. Benjamin suggests that the illusory nature of the commodity becomes apparent when it is compared with allegorical objects. Because the objects used in allegory are incapable of expressing the full meaning of the concepts they symbolise, such as death or the dangers of avarice, the relation between the object and its sign-value is trivialised and exposed as a construction (Benjamin qud. in Buck-Morss, p. 179). In the anorexic body the ideal of the healthy, slender body is exposed as a construction with a destructive passion; a demonstration of the logical end point for the aestheticised body as a commodity-fetish. It oscillates between life and death, an uncanny image.

Ernst Jentsch characterised the uncanny as confusion between animate and inanimate that occurs when a seemingly inanimate object appears to come to life or vice versa. The anorexic body has the unsettling appearance of a subject without subjectivity or the horror of a corpse returning to life. Thoughts of death may be unavoidable when viewing these skeletal figures and so death infects life (Kristeva, p. 3). 
Freud argues that the sensation of the uncanny in The Sandman is created by a fear of castration that has been displaced to the fear of losing one ' s eyes. He suggests that Jensch is wrong to point to the uncertainty of Olimpia ' s life-like appearance as a cause of uncanniness (Freud, p. 138-9). But in the story it is the eyes that deceive. When Nathanael looks at Olimpia through a magnifying lens he is initially disconcerted by the "singular look of fixity and lifelessness" in her eyes. At first, he sees her as an inanimate object but his desire animates her and eventually "he fancied a light like humid moonbeams came into them. It seemed as if their power of vision was now being enkindled; their glances share with ever-increasing vivacity" (Hoffmann, p. 203).

The eyes are the part of her body to which Nathanael looks for confirmation of Olimpia's sentience; they are the source of the confusion between object and subject, living and lifeless. It seems that objects of desire and abjection are only separated by the twinkle of an eye. Perhaps that is why the photographs from the Salpêtrière were so violently marked; if the eyes of the anorexic body were allowed to return the look they might be animated by desire, bringing the corpse to life. Alternatively, if they were lifeless and fixed they would signify a living body stripped of animation and infect the viewer with death. By obscuring the eyes the body is neither lifeless nor living, or perhaps it is simultaneously both. The issue of animation has been disavowed.

In some cases The Iconographie de la Salpêtrière presents multiple photographs of hysterical anorexia comparing the body in health and illness. In all cases the eyes are obliterated. Even the healthy body is altered in a way that makes it appear more corpse-like; the eyes resemble the hollow eye sockets of a skull. It seems that the healthy body also had to be dehumanised and turned into an inanimate object that could not return the gaze. Perhaps this made the disavowal of subjectivity of the anorexic body more stable and complete.

\section{[PLACE ILLUSTRATION 1.2 (S) HERE]}

1.2 Four Photographs of a Woman showing anorexia nervosa (1892) Nouvelle Iconographie de la Salpetriere. [Journal] Wellcome Library: London.

\section{$\underline{\text { Recuperated Signs }}$}


Ironic selfies express a wide range of messages within a single scene. Frequently the body reinforces social ideals but the objects surrounding the body bring the viewer' $s$ attention to the construction of the body as a commodity fetish. Although this theory of the selfie offers the potential to smuggle new signs into popular culture, expanding the gestures and styles permitted to the body in consumer society, it also enables negative signs to be appropriated in the system of sign-value exchange. This multiplicity of connotations can have a normalizing effect on the negative signs suggested by aberrant bodies.

Although, at its most extreme, the anorexic body of thinspiration is viewed with uncanny horror, there is evidence that selfies and thinspiration are beginning to share visual characteristics. In some selfies the bodies are very slender with visible hipbones and ribcages, bodily characteristics that are usually associated with thinspiration. But the detritus of ordinary selfies surrounds the individuals. The bodies do not function as negative signs that cannot be introjected; the commodities that surround them place the body within a system of sign-value exchange that a viewer can identify with. The commodities are associated with the construction of an ideal body, inferring the visual cues of emaciation also signify idealization and desirability. Skeletal thinness appears as a style that can be identified with and appropriated when it is fashionable to do so.

Other images I have found also bear visual similarity to the emaciated selfies found on Tumblr and other mainstream image sharing websites, but they were viewed on a pro-anorexia website. The body in the photograph follows predominant thinspiration codes because it is fragmented, decapitated and posed to emphasise bones. But the untidy room behind the figure has more in common with a selfie than a thinspiration photograph. I find this noteworthy because it seems to contradict the descriptions of anorexic character traits found in psychiatry and psychoanalysis. The typical anorexic personality is characterized by perfectionism and rigidity. The anorexia sufferer fears making mistakes and may display obsessive-compulsive tendencies. The need to control food intake coincides with a need to regulate all aspects of life; everything has to be neatly organised and under strict control (Naser et al., p. 61). Disorganisation and clutter would cause anxiety for the anorexic. The bedrooms 
behind the emaciated figure in the thinspiration photographs do not connote a pathological demand for control. Rather it suggests the codes of the emaciated body celebrated in thinspiration have been absorbed into popular culture, normalized and then disseminated as an ideal body. It seems that all signs can be recuperated within the system of sign value exchange even if they appear to be signifiers of ill heath, death and a refusal to consume.

\section{Beyond Sign-Value Exchange}

Michel de Certeau says the skin becomes a parchment written with rules and regulations when it is shaped by cultural norms. Until this process of intextuation begins, the body is not authorized or recognized by society. As de Certeau says the body is 'essentially a flesh, which writing changes into a body ' (de Certeau, p . 145), turning it into an identity that 'can be read and quoted by others' (de Certeau, p . 149). The individual must standardise the body in return for social meaning. This offers a way of interpreting the appeal of selfies and other forms of online self-presentation; although the individuals follow strict aesthetic rules for the body, they are validated by the online community and given acceptance. Selfie producers turn their bodies into signifiers of rules while giving the abstract rules material form, making it 'real' . De Certeau suggests that the body might break free from social control during moments of intense pleasure or pain. He says,

the only force opposing this passion to be a sign is the cry, a deviation or an ecstasy, a revolt or flight of that which, within the body, escapes the law of the named. Perhaps all experience that is not a cry of pleasure or pain is recuperated by the institution. All experience that is not displaced or undone by this ecstasy is captured by "the love of the censor," collected and utilized by the discourse of the law. It is channelled and instrumented (de Certeau, p . 149).

It seems the anorexic body is recuperated by the system of sign value exchange because it embodies a rational, puritan work ethic that can be "channelled and 
instrumented" by social regulation. For 'flesh' to be out of control it cannot be turned into a body by the system. If the pain of self-starvation can be appropriated in commodity culture perhaps the pleasure of eating, when it is not bound by social propriety and disapproval of the overweight body, could remove the eater from the demands of culturally coded sign values.

The disruptive potential of the over-eater can be discerned in the attempts to transform her/him into a productive consumer. Sexual, medical and commercial gazes try to create both a feeling of shame and a desire for health in the subject, while a plethora of products and services are offered to achieve this aim. For example, the diet industry promotes products that seem to permit both imperatives to delay gratification and seek reward. Diet food, characterised by chocolate, crisps and milk shakes, are the temptation and the solution for temptation. These products keep the craving to consume alive while enabling the consumer to demonstrate an acceptable work ethic and the desire to acquiesce to social norms. Consumers are transformed from shamed docile bodies into active confessional ones by turning their aberrant consumer behaviour into a form of consumption that produces sign-value for the body. There is an in-built obsolescence to this system because calorie control and restriction of food can cause the metabolism to slow down, resulting in greater weight gain. Change takes place in the relationship between the consumer and society, and not in the physical characteristics of the consumers' bodies. They yield to social regulation and the system of sign-value; the pleasure of eating chocolate and crisps is transformed into a culturally regulated activity.

The food addict turns these social regulations on their head, "transforming freedom into determinism and desire into need. Rather than consuming to realise the self, in the state of addiction, the individual is consumed by consumption" (Reith, p. 286). This form of food consumption is not productive; it does not create energy that will be transformed into labourvalue or to signify health that infers social status. It fails to conform to the protestant work ethic required by capitalism. Gerda Reith suggests that addicts appeared in great numbers when the demand to choose from an endless variety of commodities became most insistent. The occurrence of a large variety of 
types of addiction signifies "a refusal of choice that has become overwhelming; a denial of freedom that is illusory" (Reith, p. 296).

The food addict' $\mathrm{s}$ binge is said to be a capitulation to the world of commodity consumption. It is described as " $\cdots$ the relief, the letting go, the taking in, the attempted meeting of desire $\cdots$ Her wanting and wanton part is in ascendancy $\cdots$ She goes from food to food looking for the one that will satisfy her..." (Orbach, a, p. 123). The lure of novelty and the "hell of the new as the always-the-same" (Benjamin qud. in Buck-Morss, p. 211) could be discerned in this mechanical, joyless mode of eating. The commodities are stripped of content; they lose their taste, texture and aroma. Things that appear to be objects of satisfaction are quickly revealed to be dissatisfaction in disguise. These analyses of binge eating and food addiction assume that all experiences of uncontrolled eating are devoid of pleasure and wilful choice. But it is my hypothesis that it is precisely pleasure that is under attack in the disparagement of body fat and over-eating.

There is a historical precedent for the vilification of fat based on a longstanding link between sexual appetite and appetite for food. The slender body has long been coded as restrained and self-denying in both forms of carnal desire. In the Victorian era the thin body came to signify an ideal passivity and lack of desire. The slender body also signified the weakness and fragility of an upper or middle class person who did not have to work for a living. In opposition to the association between thinness and desirable virtuosity, the plump body was associated with uncontrolled impulses and working class coarseness (Krugovo Silver, p. 11-2).

In 1895 Caesar Lombroso and Guglilmo Ferrer co-authored The Female Offender, a study that analysed the body types of female criminals in order to identify degenerate characteristics. Lombroso cites data published by Fornasari in Sulla Statura degli Italiani, (Milan, 1873) which compares the age, height and weight of prostitutes with those of 'moral women' and finds that 'height and age being equal, the weight is greatest among prostitutes' (Lombroso and Ferrero, p. 50). The differentials in this experiment are illicit sexual activity and greater than normal weight, therefore the relation between them is proven. 
Sexual wantonness and over-consumption are neatly tied together in another symbol of degenerate consumption, the prostitute.

To a Victorian, being overweight demonstrated that an individual was unable to eat with appropriate restraint and decorum; it suggested that she/he was sexually voracious, possibly to a criminal degree. Multiple strands of moral, medical and judicial control were used to repress fat bodies. The variety and multitude of discursive practices used to vilify fat bodies could suggest they pose a threat to capitalist order.

In contemporary consumer society, fat is still controlled by a wide range of discursive practices. In popular culture, a television programme called Supersize vs Superskinny thinly veils the intextuation of an ideal body type beneath the pursuit of health. In each episode of Supersize vs Superskinny an overweight participant is paired with an underweight participant and they swap diets. The pairing of a tiny body with a cornucopia of food, and a large body with a meagre portion creates a grotesque scene. Indeed, the explanatory voiceover in the first episode of series one informs the viewer that "Dr Christian Jessen will be stuffing the superskinny ' - and starving the supersized" (Channel4 Production, Jenette and Rosemarie). The language is coarse and purposefully emphasises the two bodies as "uncivilised." Neither participant adheres to a socially acceptable manner of eating, so Dr Jessen employs medically dubious methods to intextuate their 'starving' or 'stuffed' flesh into consuming bodies.

The disjuncture between culture and flesh is signified by the choice of the term 'feeding clinic' for the setting of Supersize vs Superskinny. In episode eleven of season five the voiceover announces "It' $s$ dinner time in the feeding clinic," which immediately brings to mind an impression of a person throwing food to animals, perhaps on a farm or in a zoo (Channel4 Production, Anorexia). To use the word feeding rather than eating or dining is incredibly dehumanising. As Niall Richardson says:

Like all mammals, humans need to eat and, in order for the species to continue, need to have reproductive sex. However, it is the way we have 
disciplined or regimented these activities which distinguishes us from our household pets $\cdots$ In short, for humans the sexual is cultural. The same can be said for food (Richardson, p. 103).

The way we eat is not simply fulfilling a basic need; it is shaped by cultural rules and regulations. Richardson says a person eating excessively, at the wrong time or in an improper manner appears to have "ignored the dictates of culture and has yielded to base, animal urges" (Richardson, p. 104). Although the 'feeding clinic' becomes the temporary home for both participants, the name dehumanises the supersize individual to a greater extent because she/he is the one that 'feeds'. The thin body consumes reluctantly, nibbling rather than gorging. She/he remains within culturally coded dining, eating at the correct times, without indication of voracious appetite and animalistic urges.

Dr Jessen visually demonstrates the differences in supersize and superskinny diets by placing each participant' s typical weekly food intake into a transparent tube. When mixed together and viewed in this unusual way, the contents become unrecognizable as food. It appears to have been abjected from the body as vomit, or perhaps the feeding tube symbolizes a transparent body with stomach contents swimming in bile. The food is presented in a manner that seems to hover between scientific experiment and bodily process.

The intention of the television programme is to vilify rather than celebrate over-eating so the food must be transformed from desirable to abject material. Both participants are encouraged to treat the content of the tubes with disgust. For the superskinny person who already demonstrates an aversion to food this probably does not come as much of a shock. But for the supersizer who takes pleasure in eating, this must be an uncomfortable experience of aversion therapy. This individual is being trained to treat a source of pleasure with disgust. The tubes symbolize the intextuation of eating; the participant must eat with scientific precision, weighing ingredients and balancing calorie intake with energy expenditure. It symbolizes the flesh being inscribed as a body.

Throughout their participation on Supersize vs Superskinny the underweight person is presented with a seemingly endless succession of 
gargantuan unhealthy meals while the overeater is subjected to small quantities of bland food. It is the bland and repetitive diet of the superskinny participant that seems to demonstrate mechanical, joyless eating common in descriptions of binge eating and addiction. The supersize participant watches with pleasure as the superskinny tucks in to her or his favourite food. The supersize participant' $\mathrm{s}$ excitement is palpable, as they smell the aroma of the food and probably imagine the taste and texture that accompanies it. This indicates to me the pleasures of the flesh practiced outside the bounds of cultural control.

\section{Hysterical Identification and Anti-Pleasure}

At the beginning of each episode of Supersize vs Superskinny all the participants in the series line up in their underwear - the supersized on one side and the superskinny on the other. Dr Christian Jessen is situated between the two groups of people, and so is an old fashioned weighing scale. The weighing scale is the means of judgment for these bodies; it will chart the participant' $\mathrm{s}$ journey toward social acceptance. When I watch Supersize vs Superskinny I identify with the doctor and the weighing machine, putting myself in the privileged position of socially acceptable body type. In my mind, the excesses of indulgence and self-denial fan out to either side of me. This visual message clearly demonstrates the parameters of the acceptable body.

The bodies awaiting judgment at the beginning of each episode are wearing 'standard-issue' underwear; the garments are neither ornate nor individualistic, they do not represent the wearer' s personal tastes or attempt to conceal the body in a way that is flattering or incites the sexual curiosity of the viewer. The garments are de-eroticising and standardizing. The bodies are reduced to objects of inspection for the medical scrutiny of the doctor and his measuring devices.

Beneath this objective looking I catch a glimpse of a warning, the veiled threat of punishment for non-conformity. The medical objectification of these bodies suggests a loss of subjectivity; the reduction of self into an object understood through measurements and records, accumulations of information. 
Moreover, their de-sexualisation implies the loss of the right to be the object of desire for the other. For a subject assumed to be hysterical, this is a dire threat of non-existence, total eradication of self.

At the end of each programme the two participants are reunited after a number of months dieting at home. As a reward for disciplining the body each participant is allowed to choose their own underwear, often selecting bright colours and lace. The voiceover describing a superskinny participant says “... she' s even got a cleavage for the first time in her life" (Channel4 Production, Jenette and Rosemarie). The superskinny body has confessed to a television audience and submitted to discipline; its reward is to be acknowledged as an object of desire for the other. The hysterical demand "is this what you want me to be?" receives an affirmative response. The praise offered to the supersize body is couched in terms of health, rather than desirableness. It continues to be de-sexualised because it already signifies a carnal pleasure: the forbidden pleasure of eating that could destabilize cultural control.

The fat body exists outside of the system of sign-value exchange; it signifies dehumanising loss of subjectivity and animal urges, but in capitalist communities the identity that is lost is hysterical. The overeater escapes endless hysterical identifications and joyless, compulsive consumption. The dehumanising loss of subjectivity of the fat body does not connote the eradication of pleasure and destruction of the body as in the case of the anorexic. Nor does it resemble the hysterical pleasure of presentation that only resides on the surface as an image of pleasure. The overeater experiences pleasure outside the reach of capitalist signification; she/he has the cake and is allowed to eat it too.

\section{Works Cited}

Appignanesi, Lisa. Mad, Bad and Sad: A History of Women and the Mind Doctors from 1800 to the Present. 2nd edn. London: Virago, 2009.

Baudrillard, Jean. For a Critique of the Political Economy of the Sign. Translated by Charles Levin. Missouri: Telos Press, 1981. 
Benjamin, Walter. The Writer of Modern Life. Edited by Michael W. Jennings. Massachusetts: Harvard University Press, 2006. (1913-1940).

Buck-Morss, Susan. The Dialectics of Seeing: Walter Benjamin and the Arcades Project. Massachusetts: MIT Press, 1991.

Channel 4 Production. "Jenette and Rosemarie." Supersize vs Superskinny. Season1, Episode1. Director Unknown. 22 January 2008. Channel 4 Production: London, 2008. Television Broadcast.

Channel 4 Production. “Anorexia” Supersize vs Superskinny. Season5, Episode11. Director Unknown. 7 August 2012. Channel 4 Production: London, 2012. Television Broadcast.

Charcot, Jean Martin, Iconographie photographique de la Salpêtrière, Paris: La Salpêtrière Hospital, 1878.

Crawford, Robert. "A Cultural Account of "Health": Control, Release, and the Social Body." Issues in the Political Economy of Health Care, edited by J. McKinley. 60-103. London: Tavistock, 1984.

David-Ménard, Monique. Hysteria From Freud to Lacan: Body and Language in Psychoanalysis. Translated by Catherine Porter. 2nd edn. Ithaca and London: Cornell University Press, 1989.

De Certeau, Michel. The Practice of Everyday Life. Translated by Steven Rendell. Oakland: University of California Press, 1988.

Didi-Huberman, Georges. Invention of Hysteria: Charcot and the Photographic Iconography of the Salpetriere. Translated by Alisa Hartz. Massachusetts: MIT Press, 2003. 
Dor, Joël, a, Introduction to the Reading of Lacan. Edited by J. Feher-Gurewich \& S. Fairfield. 2nd edn. New York: Other Press, 1989.

Dor, Joel, b, Structures and Perversions. Translated by S. Fairfield. 2nd edn. New York: Other Press, 2001.

Dworkin, Shari L., and Wachs, Faye, Linda. Body Panic: Gender, Health and the Selling of Fitness. New York: NYU Press, 2009.

Foucault, Michel. History of Sexuality: Volume 1 An Introduction. Translated by Robert Hurley. 6th edn. London: Penguin Books, 1990.

Freud, Sigmund. The Uncanny, Translated by D. McLintock. London: Penguin Books, 2003 (1919).

Gill, Rosalind. Gender and the Media. 7th edn. Cambridge: Polity Press, 2013.

Gremillion, Helen. "In Fitness and in Health: Crafting Bodies in the Treatment of Anorexia Nervosa.” Signs 27, (2002): 381-414.

Heath, Stephen. “Joan Riviere and the Masquerade." Formations of Fantasy. edited by Victor Burgin, James Donald, and Cora Kaplan, 45-61. London and New York: Routledge, 1986.

Hoffmann, E.T.A. 'The Sand-Man’ The Best Tales of Hoffman. Translated by J. T. Bealby. edited by E. F. Bleier. New York: Dover Publications Inc.: 1967 (1816). 183-214.

Hustvedt, Asti. Medical Muses: Hysteria in Nineteenth-Century Paris. London: Bloomsbury, 2011.

Jones, Meredith. "Cosmetic Surgery and the Fashionable Face." Fashion 
Theory. 16: 2 (2012): 193-210.

Kaplan, Louise J. 1993. "Fits and Misfits: The Body of a Woman." American Imago 50 (1993): 457-480.

Kristeva, Julia. Powers of Horror: An Essay on Abjection, 2nd edn. New York: Columbia University Press, 1982.

Lacan, Jacques, a, The Four Fundamental Concepts of Psycho-Analysis. 3rd edn. Translated by Alan Sheridan. edited by Jacques-Alain Miller. London and New York: W.W. Norton \& Co, 2004 (1973).

Lacan, Jacques, b, The Seminar of Jacques Lacan: Book XX Encore 1972-1973. 2nd edn. Translated by Bruce Fink. edited by Jacques-Alain Miller. London and New York: W.W. Norton \& Co, 1998 (1975).

Lavanchy, Pierrette. "Anorexia and Femininity." European Journal of Psychoanalysis. 6. Winter (1998): 109-123.

Lombroso, Caesar and Ferrero William. The Female Offender. edited by W. Douglas Morrison. New York: D. Appleton and Company, 1895. Accessed July $25,2015$.

https://archive.org/stream/femaleoffender00lomb\#page/50/mode/2up

Marx, Karl. Economic and Philosophic Manuscripts of 1844. Translated and edited by Martin Millligan. Virginia: Wilder Publications, 2011.

Mitchell, Juliet. Mad Men and Medusas: Reclaiming Hysteria. New York: Basic Books, 2000.

Nasser, Mervat, Baistow, Kkaren, and Treasure, Janet. Editors. The Female Body in Mind: The Interface between the Female Body and Mental Health. Hove and New York: Routledge, 2007. 
Orbach, Susie. a, Fat is a Feminist Issue. 2nd edn. London: Arrow, 2006.

Orbach, Susie. b, Hunger Strike: The Anorectic's Struggle as a Metaphor for Our Age. 2nd edn. London: Penguin, 1993.

Pietz, William. “The Problem of the Fetish, II: The Origin of the Fetish.” Res 13 (1987): 23-45.

Reith, Gerda. "Consumption and its Discontents: addiction, identity and the problems of freedom.” The British Journal of Sociology 55.2 (2004): 283-300.

Richardson, Niall. Transgressive Bodies. Farnham: Ashgate, 2010.

Riviere, Joan. "Womanliness as a Masquerade." The International Journal of Psychoanalysis 10, (1929): 303-313.

Schor. Naomi. "Fetishism and Its Ironies" in Fetishism as Cultural Discourse. edited by Apter, Emily, Pletz, William. (New York: Cornell University Press, 1993). 92-100.

Silver, Anna Krugovo. Victorian Literature and the Anorexic Body. Cambridge: Cambridge University Press, 2002.

Unknown Author, 'Pro-Ana Distractions' <http://www.prothinspo.com/proanadistractions.html> [accessed April 9, 2015]

Unknown Author, 'Diet Distractions and tips for Not Eating' <http://myproanorexialife.blogspot.co.uk/2013/04/dietsdistractions-andtips-for-not.html> [accessed 9 April 2015] 


\section{Biography}

Dr Dawn Woolley is an artist and research fellow at Leeds Arts University. Recent exhibitions have included; "Self/Selfie" Ballarat International Foto Biennale, Australia (2017), "Le Féminin" Circulation(s), Arles (2017), "From Selfie to Self-Expression" Saatchi Gallery, London (2017) and "Basically. Forever" Tokyo Metropolitan Museum of Photography (2014). Her forthcoming publication Consuming the Body: Capitalism, Social Media and Commodification is due to be published in 2019 by I B Tauris. 